\title{
Memórias de migração na Amazônia:um estudo a partir das narrativas orais dos sujeitos no território da Transxingu
}

\author{
Memories of migration in the Amazon: a study from \\ the narratives subjects in the territory of Transxingu \\ Francivaldo José da Conceição Mendes* \\ César Martins de Souza ${ }^{* *}$ \\ José Queiroz de Miranda Neto ${ }^{* * *}$
}

Palavras-chave:

Território.

Transamazônica

Migração

Keywords:

Territory

Transamazônica

Migration

\begin{abstract}
Resumo: Esta pesquisa busca compreender quais motivos desencadearam os processos migratórios a partir da década de 1970 com destino ao território da Transxingu, uma área situada no interfluxo entre o rio Xingu e a rodovia Transamazônica que, ao longo da história, materializou as práticas sociais de diferentes sujeitos. Para isso, foram analisadas as narrativas orais de alguns desses migrantes na tentativa de compreender que tipo de relações materiais e simbólicas estes estabeleceram nesta área. No contexto desse trabalho, o conceito de território foi considerado de modo a situar o sujeito no novo espaço sem desconsiderar seu antigo território.
\end{abstract}

Abstract: This paper tries to find out some reasons why migratory processes from the 1970s to the territory of Transxingu were launched, Transxingu is the area located between the Xingu river region and the Transamazonnica road that, throughout history, materialized the social practices of different migrants. In order to do it, we analyzed oral narratives of some migrants in an attempt to better understand what kind of material and symbolic relationships they have established in this area. In the context of this paper, the concept of territory was considered in order to situate the individuals in the new space without disregarding their old territory.

Recebido em 10 de abril de 2018. Aprovado em 13 de agosto de 2018.

\section{Introdução}

Neste trabalho, aborda-se a respeito das memórias de migração dos sujeitos que se deslocaram para o território da Transxingu a partir da década de 1970. A ideia principal é compreender, a partir das narrativas orais dos sujeitos, quais motivos fizeram deflagrar o processo migratório para esta área, buscando perceber a relação estabelecida tanto com o território de origem quanto com o de chegada. Utiliza-se, aqui, a denominação "Território da Transxingu" para designar uma área no interfluxo entre o rio Xingu e a rodovia Transamazônica (BR-230), que possui componentes materiais e simbólicos construídos historicamente nas práticas sociais e no imaginário dos sujeitos que migraram para esta área. Ao se tratar da temática da migração e de seus diferentes sentidos, entende-se que há a necessidade em problematizar alguns conceitos como o de território o qual estará pautado, sobretudo, nas ideias de Haesbaert (2005).

Para Souza Martins (1982), os moradores do Nordeste e, em menor grau de outras regiões do país, foram amplamente encorajados pelo governo federal a se deslocarem para o território da "Transxingu", na década de 1970, o que gerou profundas transformações, impactando a vida

\footnotetext{
* Mestrando em Linguagens e Saberes na Amazônia no Programa de Pós-Graduação em Linguagens e Saberes da Amazônia da Universidade Federal do Pará (UFPA). E-mail: francivaldo.edfisica@gmail.com

** Doutor e Pós-Doutor em História pela Universidade Federal Fluminense. (UFF) Professor do Programa de Pós-Graduação em Linguagens e Saberes da Amazônia e do Campus de Altamira, da Universidade Federal do Pará (UFPA). E-mail: cesar@ufpa.br.

*** Doutor em Geografia pela Universidade Estadual Paulista (UNESP), Campus de Presidente Prudente. Professor da Universidade Federal do Pará (UFPA).E-mail: mirandaneto@ufpa.br.
} 
das populações da região, sobretudo indígenas e ribeirinhos. Na concepção de Velho (1995), a forma como foram organizados os deslocamentos de populações para a Amazônia, durante a ditadura, consolida um projeto mais amplo de capitalismo autoritário, que ignora as populações locais e pensa as terras como forma de gerar capital, ignorando-se práticas sociais nelas existentes.

No estudo de Souza (2014), o autor narra diversas histórias envolvendo os migrantes, sobretudo nordestinos, por meio das quais são retratadas as adversidades de infraestrutura encontradas, a precariedade das políticas públicas para a região. Paralelamente a isso, coexistia no discurso institucional do governo militar que essa área deveria ser ocupada e colonizada. Por essa razão, entende-se a necessidade de encontrar, mais de 40 anos após o início desse processo, tanto as marcas da colonização deixadas na memória do migrante pioneiro como as formas pelas quais esse sujeito ficou envolto em um novo laço de significados após a chegada ao novo território.

As narrativas dos sujeitos obtidas ao longo desse trabalho constituíram-se em uma estratégia metodológica privilegiada, uma vez que facilitou a compreensão das trajetórias desses migrantes. Esses sujeitos são oriundos de três regiões distintas do Brasil, tendo chegado à região da "Transxingu" a partir da década de 1970. As entrevistas abertas utilizadas nessa pesquisa possibilitaram entender de que forma tais sujeitos remetem aos territórios de origem e de chegada e, paralelamente, indicam como essas pessoas se relacionam como o novo território.

Neste trabalho, os sujeitos entrevistados serão identificados pelas iniciais dos respectivos nomes, a fim de que se preservem suas identidades. O primeiro, P.M.M., natural de Goioerê no estado do Paraná; o segundo O.S.R., natural de Vitória da Conquista, localizada no estado da Bahia; e a terceira F.C.M., natural de Ipixuna, situada no estado do Maranhão. Entende-se que existe uma relação muito próxima entre o sentir-se pertencente ao novo território e a existência da propriedade (e do usufruto) da terra, um elemento importante para o estabelecimento de raízes territoriais na "Transxingu”.

\section{Ciclos econômicos e a dinâmica migratória no território da Transxingu}

A dinâmica migratória na Amazônia é marcada por diferentes ciclos e ações políticoeconômicas que constantemente (re)definiram a organização social nessa região. Com atividade extrativa das drogas do sertão e, posteriormente, com a economia da borracha, a lógica do convencimento pela fé e das disputas militares é substituída pelo poder econômico e pelo domínio político dos coronéis (WEINSTEIN, 1993).

Para Santos (1980), entre o final do século XIX e meados do século XX, os seringalistas passaram a conduzir a vida econômica e social da região dos centros de exploração da borracha na Amazônia. Na lógica do sistema de aviamento ${ }^{1}$, a região crescia economicamente, mas ao mesmo tempo via os trabalhadores serem colocados à margem do processo em uma condição de semiescravidão. Na primeira fase de expansão da economia da borracha (final do século XIX), uma das principais dificuldades foi a ausência de mão de obra. Nesse caso, duas alternativas foram postas em prática: a utilização do trabalho indígena e a importação de colonos do exterior, ambas sem sucesso (TEIXEIRA, 1980). A solução veio com a imigração nordestina, conforme aponta Santos (1980, p. 97) "o braço externo de sustentação da atividade extrativa e agrícola foi, por excelência, o nordestino". Uma parte importante desses trabalhadores ocupou os vales do Xingu e passou a trabalhar na extração do látex, da castanha e de outros produtos secundários.

Souza e Serra Neto (2008) analisam como Altamira, em 1911, passou da condição de vila, pertencente a Souzel, para a condição de cidade emancipada, a partir do grande crescimento populacional e econômico, principalmente a partir da borracha. Entretanto, por volta de 1940, segundo o Instituto Brasileiro de Geografia e Estatística (IBGE, 2010), a população do município reduziu em 30\% em função da crise da borracha, implicando o fechamento de seringais falência das casas aviadoras. Após esse declínio, outras atividades se 
desenvolveram nas proximidades do rio Xingu, como a chamada "febre da fantasia" de comércio de peles de animais, assim como a pecuária bovina, que em 1968 já representava mais de $30 \%$ do total da produção (BRASIL, 1970).

Foi, entretanto, a partir da década de 1970 que se verificou o verdadeiro boom do processo migratório para a área entre o Xingu e Transamazônica. A criação de instituições como Superintendência do Desenvolvimento da Amazônia (SUDAM) e Banco da Amazônia S/A (BASA) e a construção da rodovia Transamazônica, possibilitou um processo de colonização em larga escala a partir da criação do Programa Integrado de Colonização (PIC). Nesse novo contexto, a área situada entre o rio Xingu e a recém-criada rodovia Transamazônica (BR-230) se consolida como um verdadeiro ponto de interseção dos processos migratórios. Como aponta Becker (1990), a maior área ocupada se situava nas proximidades do município de Altamira, com 3.759.500 hectares, para onde se dirigiram mais de seis mil colonos. Tal processo teve consequências cruciais para o crescimento populacional na região, conforme aponta Miranda Neto (2016) a população da região passou de pouco mais de 59 mil para 186 mil habitantes, multiplicando-se em três vezes.

De acordo com Souza (2014), as políticas migratórias seguiram um ordenamento de política nacional na perspectiva de preenchimento de vazios demográficos. Essa concepção foi utilizada como justificativa pelo governo militar para incentivar o processo migratório. Paralelamente, o discurso oficial trazia à tona a necessidade de se promover a "conquista da Amazônia", aliado ao que à época convencionou-se chamar de "integração nacional".

Em relação à política nacional para a Amazônia, Miranda Neto (2016) destaca como fato relevante a política de implementação dos grandes projetos a partir da década de 1990 na região. Para este autor, tais projetos obedecem a uma lógica transnacional subordinada ao grande capital econômico, tendo nos recursos naturais seus maiores expoentes. Em estudo recente, o autor cita o caso da construção da Hidrelétrica de Belo Monte como sendo o maior projeto de infraestrutura do começo do século XXI na Amazônia. Para o autor, projetos como estes fazem deflagrar incontáveis reflexos ambientais e sociais, um deles é o grande fluxo migratório induzido pela construção de obras desse porte. De acordo com o autor, uma parte importante dos migrantes que veio trabalhar em "Belo Monte" é originária do Nordeste do país, a exemplo do estado do Maranhão que, sozinho, oferta 19\% da mão de obra para o projeto hidrelétrico (MIRANDA NETO, 2016). Os dados relacionados a Belo Monte, ainda que não estejam diretamente no escopo deste artigo, são inseridos aqui para que se possa refletir a respeito do caráter de "fronteira de expansão" (BECKER, 1990) que envolve o território da Transxingu.

A região em torno do rio Xingu, que, segundo o viajante naturalista Henri Coudreau (1977), experimentou um grande fluxo migratório e crescimento econômico com a exploração da borracha, no final do século XIX e depois se consolida no início do XX como centro produtor da goma elástica, vivencia um período de estagnação, após o declínio da exploração do látex na Amazônia. Esse quadro somente sofreu alteração significativa, com a construção da rodovia Transamazônica (BR-230), durante o governo do general-presidente Emílio Garrastazu Médici (SOUZA, 2014).

Como podemos analisar a partir de Martins (1982), a construção da BR-230, na década de 1970, inaugura um momento em que as referências identitárias dos sujeitos da região, passaram a reunir como forte elemento de coesão, a presença do rio Xingu e da rodovia Transamazônica (BR230), suscitando a existência de um território que não se restringe aos limites municipais: o território da Transxingu (Figura 1). 


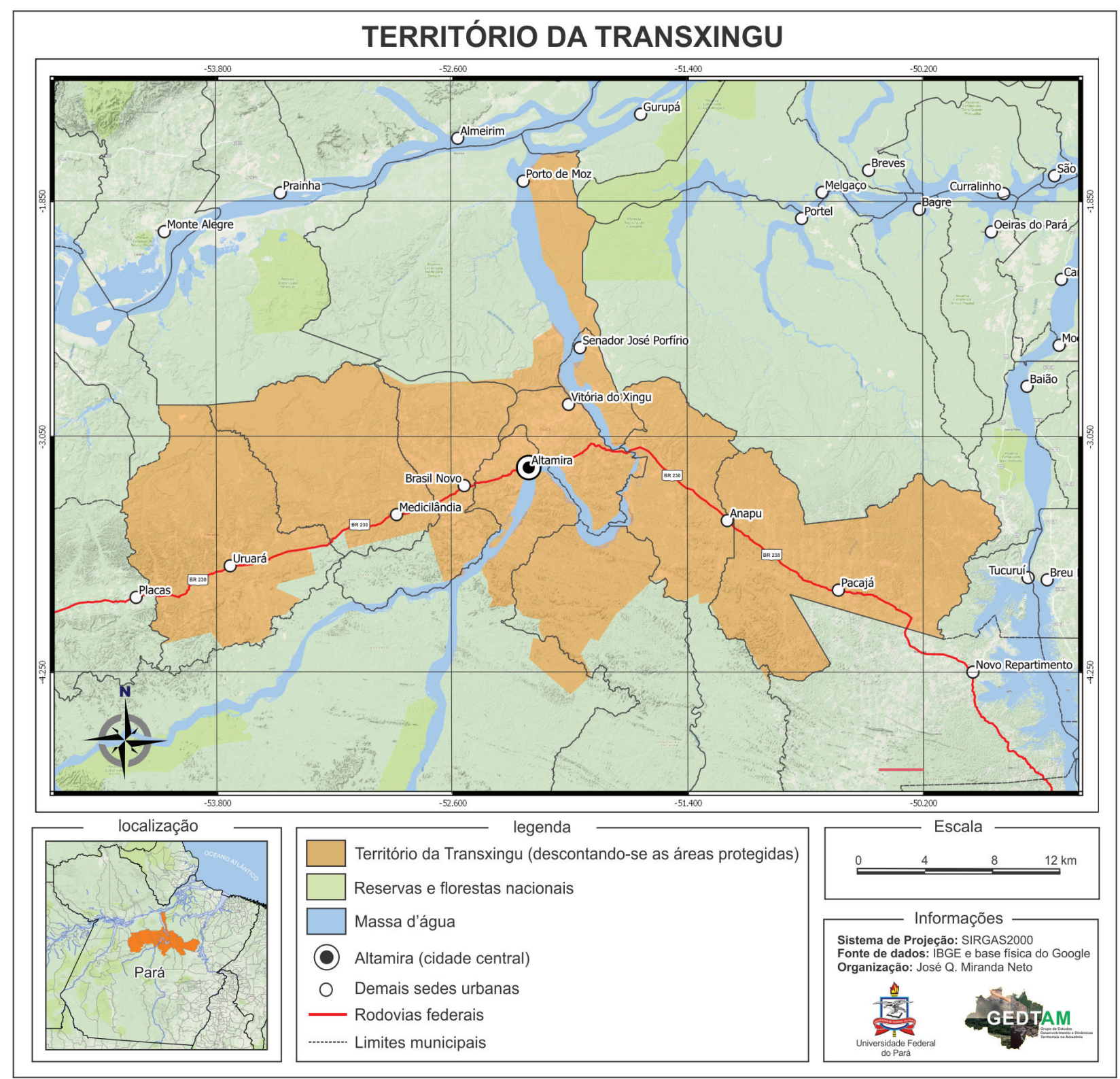

Figura 1: Território da Transxingu

Fonte: Miranda Neto (2018).

A área identificada pela Figura 1 demarca não apenas um espaço político, mas um território integrador de experiências econômicas, ambientais e simbólicas. Na perspectiva de compreender o processo migratório no território da Transxingu. Desse contexto, não se pode deixar de considerar a presença de um centro que articula várias cidades ao seu entorno. Este é o caso de Altamira, que desempenha papel estratégico na confluência da rodovia BR-230 e, também, ao rio Xingu. $\mathrm{Na}$ análise de Miranda Neto (2016), a cidade de Altamira desempenhou um papel centralizador do ponto de vista da logística para que a usina Belo Monte se efetivasse.

Durante o período de construção da obra, a cidade passou por visíveis alterações. Miranda Neto e Herrera (2016) apontam para a constante mudança demográfica pela qual passa a cidade de Altamira. Neste estudo, afirmam que a cidade saiu de uma população de 75 mil para algo em torno de 120 mil habitantes apenas no seu perímetro urbano (MIRANDA NETO; HERRERA, 2016).

Os dados trazidos ao debate reforçam esse quadro histórico de migração que acompanha a área 
ao longo da Transamazônica, com ênfase na cidade de Altamira. Pode-se perceber que a dinâmica de ocupação dessa região obedece a períodos que quase sempre coincidem com a implementação de grandes obras. Foi assim ainda no século XIX com a exploração da borracha e em meados do século XX, fruto de uma política nacional desenvolvimentista, com a abertura da rodovia transamazônica e, atualmente, com a construção de hidrelétricas e projetos de extração de minérios, ampliando-se a presença de migrantes nessa região.

Conforme já foi mencionado, em 2017 é estimada para a cidade de Altamira uma população de 111.435 habitantes. Além disso, é importante observar o gráfico da Figura 2, pois este evidencia o surto demográfico pós-1970, período da abertura da rodovia Transamazônica. É válido frisar que, à exceção dos anos anteriores a 1970, a maior parte da população encontrava-se na área urbana da cidade, o que confirma seu papel articulador e de polo na prestação de serviços aos demais municípios da região. Em 2010, observou-se que das $98 \mathrm{mil}$ pessoas residentes no município mais de $80 \mathrm{mil}$ encontravam-se no perímetro urbano da cidade.

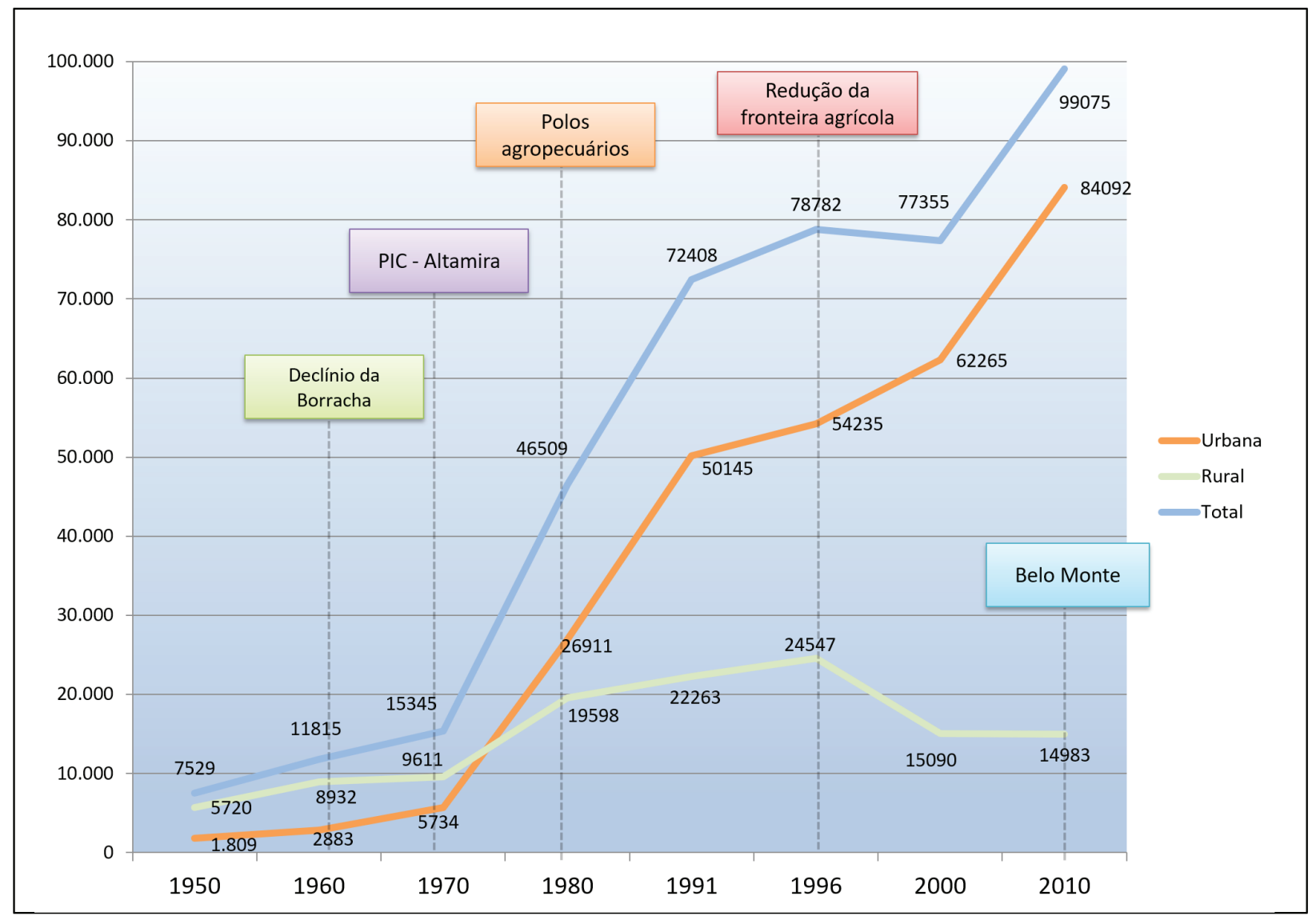

Figura 2: Evolução da população urbana, rural e total do município de Altamira Fonte: Instituto Brasileiro de Geografia e Estatística (2010).

Tendo em vista a definição do território em estudo e das condições estruturais ligadas ao processo migratório para esta área, parte-se agora para a composição do marco analítico necessário para a análise, conforme se verá a seguir. 


\section{Dos processos migratórios à constituição de novos territórios}

Em que pesem as discussões acerca da migração, os estudos de Sayad (1998) podem vir a se constituir em um relevante referencial teórico para compreender os processos investigados nesse estudo. Nos estudos desse autor, algumas características evidenciam os principais motivos que levam as pessoas a migrarem, indo desde eventos naturais até ações no campo político-econômico.

No caso dos migrantes ouvidos nesse trabalho, os motivos de terem saído dos seus espaços são variados, mas em comum tem-se o fato de procurarem terra para cultivarem e se estabelecerem em outro território. É importante mencionar esse aspecto do território, pois exige muito desses sujeitos que, a rigor, enfrentaram desafios de ordem multifatorial no novo espaço.

$\mathrm{Na}$ tentativa de relacionar os processos migratórios com a perspectiva da territorialidade os estudos Haesbaert (2005) podem indicar uma boa articulação. Para esse autor, a dimensão do território não é somente física, mas também simbólica e demarcadora de identidades. Assim, território e migração implicam, a depender do tempo-espaço, variadas conotações, uma vez que assumem diversos sentidos para quem o exerce.

Em linhas gerais, no caso da colonização da transamazônica, podem-se notar duas formas de inserção das pessoas no território. A primeira, induzida pelo governo, com fomento e uma razoável assistência. A segunda, diz respeito a um processo relativamente independente. Nos dois momentos, os sujeitos que migraram para o território possuíam características elementares que os diferenciava, quer seja pela motivação do processo migratório, quer seja pelo espaço que passou a ocupar no novo cenário.

Para Haesbaert (2005), é preciso distinguir a desterritorialização dos "dominantes" e de outros grupos. Para exemplificar, o autor cita no caso de um migrante nigeriano sem posses e a de um executivo. Embora ambos estejam na condição de migrantes, uma diferença social significativa os separa, pois socialmente os dois ocupam posições bem definidas na hierarquia social e conclui seu raciocínio por afirmar que nem sempre migração pressupõem mobilidade social. Para o autor, os ricos vivenciam uma forma de migração muito diferente das demais classes, que pressupõem uma situação segura do ponto de vista social. Por outro lado, os indivíduos desfavorecidos socialmente experimentam, ao migrarem, uma situação de incerteza e de insegurança social.

Considerando as ideias de Haesbaert (2005) e de Sayad (1998) sobre território e processos migratórios, chega-se à questão central do trabalho proposto: "de que maneira o sujeito que migrou para o território da Transxingu a partir da década de 1970 se situa diante dessa nova área geográfica?". Esses e outros apontamentos norteiam essa análise. Em Sayad (1998), inexiste "inocência" em processos migratórios; afinal, pois quem o faz, age dentro de uma lógica de ordenamento subjetivo ou induzido por outros fatores.

\section{Memória dos migrantes no território da Transxingu}

Falar de migração no território da Transxingu é lançar o olhar para o interior de um Brasil, por vezes, não conhecido nos relatos oficiais. Assim, é se esforçar para compreender que os homens e mulheres que aqui chegaram, em geral induzidos por uma forte propaganda oficial, viram-se num dado momento desassistidos e, às vezes, impotentes ante a realidade que se colocava diante deles. Os recorrentes problemas sanitários e as dificuldades de locomoção são algumas das características que fazem desse território um espaço desafiador para quem por aqui chegou e viveu nesse espaço nessas mais de quatro décadas.

Ao conversar com o entrevistado P.M.M., este afirma que as pessoas que chegavam em Altamira advinham quase sempre do nordeste do Brasil, influenciados pela propaganda oficial. Os relatos desse migrante, narram o frenesi que era a cidade naquela época: tudo nos pequenos mercados acabava rapidamente, as caminhonetes saiam em direção a oeste a todo momento levando os recémchegados para a tão propagandeada "terra". Em geral, faziam uma parada no Km 23 Altamira-Itaituba na 
“vila do João Pezinho", uma espécie de representante local do governo federal, e, então, seguiam no sentido do que hoje são as cidades de Brasil Novo, Medicilândia, Uruará, Placas, Rurópolis.

Ao analisar o processo migratório de italianos para a Amazônia, da segunda metade do século XIX a primeira metade do XX, Emmi (2008) afirma que tais pessoas carregavam consigo o sofrimento pelo que deixam e a ansiedade pela nova realidade desconhecida. Dessa forma, as lembranças de sua antiga cidade, de seus antigos vizinhos, de suas redes de sociabilidade davam agora lugar a um novo cenário, uma nova configuração marcada por uma dinâmica social diferenciada. Coutinho (2005) retrata as narrativas de uma migrante gaúcha que muito estranhava o novo espaço com os novos sujeitos e costumes. O relato dessa migrante gaúcha se passa quando esta, hospedada na "vila do João Pezinho", sentia-se muito incomodada com homens nordestinos que transitavam com naturalidade sem estarem vestidos com uma camisa.

Em Halbwachs (1990), entende-se que há tantas memórias quantos os grupos existentes e que nós nunca nos lembramos sozinhos. Para esse autor, a manutenção de um grupo pressupõe a existência da sua memória, de modo que a memória tem fortes ligação com o "espaço" vivido coletivamente, implicando no que o autor chamou de "quadros sociais". São, portanto, esses quadros que dão sentido a estruturação da memória no aspecto coletivo.

Em sua tese sobre as mulheres migrantes na Transamazônica, Coutinho (2005) narra as estratégias coletivas criadas pelas migrantes e suas famílias no novo território. Essas estratégias vão desde a "almoços comunitários, grupos de vizinhos"2, até a inserção em campos políticos estratégicos, como a presidência de sindicatos, associações, legislaturas municipais, estaduais e até federais. Para a autora, essas estratégias coletivas diante do novo território imprimiram novos significados ao fazer cotidiano de todos os sujeitos que saíram dos seus espaços, em geral do nordeste do Brasil. Dessa forma, as ações coletivas como as narradas acima fortalecem o grupo diante das inúmeras dificuldades encontradas no novo espaço.

Em seu livro "Anamã: fogo nas águas do Amazonas", Portugal (2016) narra a história de migrantes que iam em direção ao município de Brasil Novo (cidade a 46 quilômetros de Altamira). Nesta obra, é evidenciado o trágico acidente ocorrido com o barco que navegava pelo rio Amazonas vindo a pegar fogo naufragando e matando dezenas de pessoas. Em geral, os sujeitos que carregam consigo a ideia de conseguir "terra" para trabalhar e prosperar, mas quase sempre o cenário encontrado é bem diferente, impondo a quem chega um enorme desafio de permanência no espaço.

Tendo a Transamazônica como cenário, Miranda (2000) também conta, por meio de uma literatura de cordel, as várias histórias ocorridas com migrantes da região nordeste que se deslocaram para Brasil Novo na década 1970. Na obra, o autor cita o papel importante desempenhado pela igreja católica a partir dos seus representantes locais (padres, irmãs e o bispo D. Erwim ${ }^{3}$ ) e destaca a capacidade dessas pessoas em resistir mesmo diante dos vários problemas por ele elencados.

O que se percebe, a partir do que é descrito nas três obras anteriormente mencionadas, é uma vasta história de homens e mulheres que muito se assemelha com as narrativas dos sujeitos entrevistados nesse trabalho e que, do ponto de vista formal, são silenciadas ante a história nacional. Nesse sentido, torna-se relevante ouvir as vozes dos sujeitos, para que possamos conhecer suas próprias versões sobre as memórias de importantes momentos históricos, como a construção da Transamazônica, por eles vivenciado.

Para o migrante P.M.M., sair de seu local de origem era uma possibilidade de conseguir terra para plantar, um recurso que ele não possuía em sua cidade de origem e que gerava dificuldades de sobrevivência. Assim, ao ouvir a propaganda do governo federal, resolveu partir do estado do Paraná para esta terra que, segundo diziam, tinha tudo em abundância. $\mathrm{O}$ ano que chegou em Altamira foi 1976, com recursos próprios extremamente limitados, trazendo consigo sua esposa. A seguir o migrante relata o motivo da saída de sua cidade: "É falta de terra pra trabalhar, porque na época que eu sai de lá... Eu me bati pra arrumar ao menos um mei alquere ${ }^{4}$ de terra pra trabalhar e não achei nada" (Entrevistado P.M.M., 2017). 
Resposta similar foi dada pela moradora do

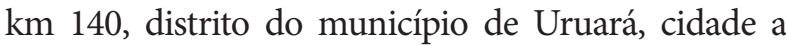
$180 \mathrm{~km}$ de Altamira (sentido Itaituba). Para F.C.M, o motivo que a levou a migrar para o estado do Pará foi:

\begin{abstract}
Ah! A gente veio para cá em busca de tirar um lote, na época meu cunhado tava aqui no estado do Pará e ele ligou pra nós pra nós vim pra cá que era no tempo que o INCRA tava buscando as pessoas no nordeste [...] em qualquer lugar do Brasil que quisesse vim aqui pro Pará ai eles trazia chegava aqui dava um lote [...] pra nós [...] nós viemos nesse prissuposto de tirar um lote [...]. (Entrevistado F.C.M, 2017.)
\end{abstract}

Sem dúvida, a falta de terra para trabalhar aliada à forte propaganda do governo federal fez com que dezenas de pessoas migrassem para Altamira dos anos de $1970 \mathrm{em}$ diante. O que se pode notar das narrativas dos sujeitos entrevistados é que eles tinham como referência apenas a possiblidade da terra. Haesbaert (2005) chama isso de território simbólico, a perspectiva de conquista de algo que pode reordenar o rumo de vida de quem almeja, nesse caso a terra.

O migrante P.M.M. narra a dificuldade encontrada por ele naquele momento. Faltava desde os recursos para se deslocar de sua cidade até a estrutura mínima para continuar a se manter no novo espaço. O diálogo estabelecido evidencia as precárias condições encontradas pelo sujeito que chegou no novo espaço, que não dispunha sequer de condições para fazer um abrigo para morar ou, ainda, condições de manter uma alimentação nutritiva. Pelo que se pode notar, mesmo diante de todas as dificuldades, ele não conseguiu ter acesso a tão esperada terra.

[...] Vim muitas vezes da $11^{5} \ldots$ Que é praticamente cinco quilômetros da faixa lá, vim de lá aqui no Brasil Novo ${ }^{6}$ e voltar com 20 ...25 quilos de compra nas costas e o dinheirinho que eu trazia era só pra comprar aquilo ali. Não tinha espaço pra mais nada, vinha a pé e voltava de a pé... Eu gostava de um cigarrinho branco, gostava de um golin de pinga, mas eu não comprava nem um litro de pinga nem uma carteira de cigarro, nem nada... Chegava aqui fazia a comprinha... botava aquilo nas costas, as vezes no inverno que quando você passava do Jarucu?. Ali você pode perguntar a qualquer pessoa que lá no Jarucu corria uma água assim que você via trairinha $a^{8}$ na beira da estrada desse tamanho assim... Lama naquele tempo... Tinha lama no mei da estrada, calçado numa bota de borracha [...]. (Entrevistado P.M.M., 2017).

Mesmo com esse cenário narrado nem todos os que chegavam conseguiam de imediato se estabelecer em uma terra, foi o caso da entrevistada F.C.M. que afirmou não ter conseguido se estabelecer de imediato em um lote, somente conseguindo a "terra própria" passados dez anos no atual município de Uruará e que, durante todo esse tempo, a estratégia de sobrevivência era trabalhar em sistema de diárias plantando cacau, pimenta do reino, cultivando lavouras em geral para os patrões. Do mesmo modo, P.M.M. afirmou que a estratégia para sobreviver naquela época era trabalhar de diárias, sobretudo no período chuvoso, momento propício para diversas plantações e reconhece que havia naquele tempo mais possibilidade de ganhar dinheiro do que no momento atual.

Nos dois casos, fica evidente que o motivo principal da migração foi a busca por terra para trabalhar. As duas histórias narradas apontam para um território desassistido por parte do governo e com inúmeras dificuldades de várias ordens, uma das principais tem a ver com a mobilidade e infraestrutura de maneira geral. Há, porém, casos de migrantes que vieram por outros motivos em outras épocas e em condições sociais diferente em relação aos dois casos já narrados. Este é o caso do migrante O.S.R., natural da cidade de Vitória da Conquista no estado da Bahia. Este ocupa uma posição social diferenciada em relação aos demais migrantes desta análise:

[...] fui pra São Paulo e, de repente, não tive sucesso em São Paulo. E retornei para a cidade de Vitória da Conquista na Bahia onde eu ingressei na Polícia Militar do Estado como recruta. Fui soldado e no ano de 79 eu fui pra escola de Sargento. Passei dois anos como Sargento, fui 
delegado de polícia e depois fui pra escola de Oficiais onde fui declarado aspirante no ano de 1984. Sai aspirante, fui $2^{\circ}$ Tenente fui promovido a primeiro depois e encerrei a minha carreira militar no ano de 1992 quando me elegi vereador de Vitória da Conquista e por força constitucional fui pra reserva " $E x$ officio"... Uma reserva remunerada como $1^{\circ}$ Tenente. (Entrevistado O.S.R., 2017).

Percebe-se que, socialmente, esse migrante ocupa outro espaço muito diferente dos demais, conforme já ensinou Sayad (1988) e Haesbaert (2005), visto que, embora este esteja em constante migração, não está na situação de insegurança ou vulnerabilidade social, uma vez que já foi parlamentar, oficial da polícia militar e atualmente é aposentado como militar. Juntos, esses atributos lhes permitem uma diferenciação social. Observase que o tempo que o mesmo migrou pela primeira vez para o território da Transamazônica foi em 1997, como afirma: "Posteriormente, depois de muito tempo trabalhando com comércio, eu fiz o curso técnico agrícola e eu vim pra Canaã dos Carajás, onde comprei uma pequena propriedade... No Pará" (Entrevistado O.S.R., 2017).

Dois fatores ratificam a afirmação da sua posição diferenciada: a primeira diz respeito a sua formação e acesso à educação, não observada nos demais migrantes; a segunda se refere ao fato de o migrante já ter chegado ao novo espaço com recursos suficientes para aquisição da propriedade. Aliado a isso, é possível verificar que, de fato, a sua perspectiva de sujeito migrante é diferenciada dos daquela época do início da década de 1970:

[...] também resolvi vender a propriedade. Fui embora e no ano de 99 (de Canaã dos Carajás) eu fui morar em Tocantins na cidade de Formoso do Araguaia. Em Formoso do Araguaia foi quando eu tive a ideia de vim mexer trabalhar com cacau na Transamazônica vindo pra cidade de Uruará, com objetivo de aproveitar minha formação técnica na área agrícola e como meu curso foi feito na CEPLAC ${ }^{9}$ Bahia, né? [...] A gente aplicar os nossos conhecimentos na área da Melhoramento Genético e reforma de lavoura em cacau na Transamazônica. (Entrevistado O.S.R., 2017).
Percebe-se que a visão do sujeito O.S.R. não é a de um "desbravar inicial" e sim de um melhoramento, de uma verticalização da produção, sempre no sentido de agregar valor ao produto da região. A narrativa do sujeito em questão denuncia uma postura de alguém que se identifica apenas parcialmente com o território, quando afirma que já esteve mais de três vezes na área e não permaneceu definitivamente em nenhuma das vezes. Esse cenário é bem diferente da moradora F.C.M, para quem é perceptível a relação de identidade com o espaço, uma vez que, quando perguntada se tem vontade de ir embora daquela região, afirma: "não, eu não tenho vontade de ir embora daqui não, só se fosse ali pra Uruará. Mas aqui mesmo no estado do Pará. Eu não tenho vontade de ir embora daqui não" (Entrevistada F.C.M., 2017).

Nas conversas empreendidas com os migrantes, éperceptível que o território da Transxingu é carregado de significados para essas pessoas, demonstrando relações muito bem estabelecidas que envolvem, sobretudo, a existência da propriedade da terra. De fato, o lugar representa uma espécie de recomeço, de construção e de intensa identidade, porque, apesar de todas as dificuldades narradas e elencadas, os migrantes não cogitam possibilidades de sair dessa área. Em suas narrativas, é perceptível que o espaço possibilitou avanços pessoais, sobretudo associados ao acesso à terra.

\section{Considerações finais}

As três histórias, brevemente narradas neste trabalho, evidenciam a face de um Brasil ainda desconhecido para a maioria dos brasileiros, é uma região historicamente vinculada a grandes projetos e, por isso mesmo, portadora de grandes reflexos e impactos sociais.

O território, neste caso, é visto como um espaço capaz de possibilitar mobilidade social, carregando na sua estrutura variados sentidos para quem migrou para este território. Ficaram evidentes as várias estratégias criadas e implementadas pelos sujeitos entrevistados ante a realidade, assim como as fortes marcas de identificação ao novo espaço.

As narrativas evidenciam, que os sujeitos vieram para esse território motivados pela 
expectativa da conquista de uma propriedade que lhes possibilitasse lidar com uma terra. Destaca-se como indutor desse cenário, a forte propaganda oficial da época, somada a inúmeras dificuldades enfrentadas seus locais de origem. Por outro lado, a perspectiva de obtenção da terra não sublima as dificuldades de várias ordens encontradas pelos sujeitos no novo espaço. As narrativas demonstram a resiliência e as várias estratégias individuais e coletivas estabelecidas pelos sujeitos com vistas a superar a desassistência governamental entre outras dificuldades. De um modo geral, os que permaneceram no território narram histórias de dificuldades, mas também de superação e de forte relação identitária com o novo espaço.

Percebeu-se que, via de regra, as políticas de Estado corroboraram para que a migração se efetivasse mesmo não sendo suficientemente efetivas na assistência desses sujeitos. De outro modo, as aspirações contidas nas narrativas de cada um dos sujeitos indicam diferenças e sinalizam para a complexa tarefa que é compreender os motivos que estão por trás dos processos migratórios.

\section{Notas}

1 Um sistema de exploração da força de trabalho derivado do escambo onde, segundo Santos (1980) "o seringueiro ficava de tal forma isolado, pela própria disposição geográfica das atividades produtivas regionais".

2 Programações vinculadas à igreja católica.

3 Bispo emérito da prelazia do Xingu e com grande influência religiosa neste território desde os anos de 1970.

4 Unidade usada para medir extensões de terra. No Brasil existem diferentes medidas, a adotada no trecho em estudo é o alqueire mineiro, área correspondente a um quadrado de lado igual a 220 metros.

5 Vicinal pertencente ao município de Brasil Novo.

6 Município a $46 \mathrm{~km}$ de Altamira sentido Santarém.

7 Igarapé a 4 km do município de Brasil Novo.

8 Peixe de escama muito comum nos igarapés da região.

9 Comissão Executiva do Plano Lavoura Cacaueira.

\section{Referências}

BECKER, Bertha. Amazônia. São Paulo: Editora Ática, 1990 (Série Princípios).
BRASIL. Serviço Federal de Habitação e Urbanismo (SERPHAU). Relatório Preliminar de desenvolvimento integrado do município de Altamira. São Paulo: SERPHAU, 1970.

COUDREAU, Henri. Viagem ao Xingu. São Paulo: Editora da USP, 1977.

EMMI, Marília Ferreira. Italianos na Amazônia (1870-1950): pioneirismo econômico e identidade. Belém: NAEA, 2008.

HAESBAERT, Rogério. Migração e Desterritorialização. In: PÓVOA NETO, Helion Póvoa; FERREIRA, Ademir Pacelli (Org.). Cruzando fronteiras disciplinares: um panorama dos estudos migratórios. Rio de Janeiro: Revan, 2005.

HALBWACHS, Maurice. A memória coletiva. São Paulo: Editora Vértice, 1990.

INSTITUTO BRASILEIRO DE GEOGRAFIA E ESTATÍSTICA. População municipal entre $\mathbf{1 8 7 2}$ e 2010. Planilha (MS Excel). 2010a. Acesso em: <http://www.ibge.gov.br/>. Acesso em: 5 set. 2017.

Estimativa demográfica em 2017. Acesso em 15/12/2-17.disponível: em: <http://www.ibge. gov.br/>. Acesso em: 10 ago. 2018.

MARTINS, José de Souza. Expropriação e violência: a questão política no campo. São Paulo: Hucitec, 1982.

MARTINS DE SOUZA, César; SERRA NETO, Itamar Zuqueto. De migrantes nordestinos a seringueiros no Xingu: história, memória e literatura em A batalha do Riozinho do Anfrísio. In: MARTINS DE SOUZA, César; CARDOZO, Alírio. Histórias do Xingu: fronteiras, espaços e territorialidades. Belém: EDUFPA, 2008, p. 215-234.

MIRANDA, José Pereira de. Transamazônica sonhos e realidade. São Paulo: Casa do Editor, 2000.

MIRANDA NETO, José Queiroz de. UHE BELO MONTE E A REESTRUTURAÇÃO DA CIDADE DE ALTAMIRA-PA: Agentes, processos 
e redefinições espaciais. In: ENCONTRO NACIONAL DA ANPEGE, 11 out. 2015. Anais eletrônicos. Presidente Prudente. São Paulo, 2015. Disponível em: <www.enanpege.ggf. br/2015>. Acesso em: 15 dez. 2017.

MIRANDA NETO, José Queiroz de. Os nexos de reestruturação da cidade e da rede urbana: o papel da Usina Belo Monte nas transformações espaciais de Altamira-PA e em sua região de influência. 2016. 370 f. Tese (Doutorado em Geografia) - Programa de Pós-graduação em Geografia da Faculdade de Ciência e Tecnologia da UNESP - São Paulo.

; HERRERA, José Antônio. Altamira-PA: novos papéis de centralidade e reestruturação urbana a partir da instalação da UHE Belo Monte. Confins, 28, 2016. Disponível em: <https://confins. revues.org/11284>. Acesso em: 5 set. 2017.

NORA, Pierre. Entre memória e história: a problemática dos lugares. Projeto História, São Paulo, n. 10, p. 7-28, dez.1993.

POLLAK, Michael. Memória, esquecimento, silêncio. Estudos Históricos, Rio de Janeiro, v. 2, n. 3, p. 3-15, 1989. Disponível em: <http://www.uel.br/ cch/cdp>. Acesso em: 15 dez. 2017.

PORTUGAL, Sônia Feiteiro. Anamã: fogo nas águas do Amazonas. Recanto das Letras, 2016

SANTOS, Roberto. História econômica da Amazônia (1800-1920). São Paulo: T. A. Queiroz, 1980.
SAYAD, Abdelmalek. A imigração ou os paradoxos da alteridade. Tradução de Cristina Murachco. São Paulo: Editora da Universidade de São Paulo, 1988.

SILVA, Maria Ivonete Coutinho da. Mulheres migrantes na Transamazônica: construção da ocupação e do fazer política. 2008. 293 f. Tese (Doutorado em Ciências Sociais) - Programa de Pós-Graduação em Ciências Sociais, Universidade Federal do Pará, Belém, 2008.

SOUZA, César Martins de. Ditadura, grandes projetos e colonização no cotidiano da Transamazônica. Revista contemporânea - dossiê 1964-2014: 50 anos depois, a cultura autoritária em questão, v.1, n. 5, ano 4, 2014, p. 1-19, 2004.

TEIXEIRA, Carlos Corrêa. O aviamento e o barracão na sociedade do seringal: estudo sobre a produção extrativa de borracha na Amazônia. 1980. 250 f. Dissertação (Mestrado em sociologia) Faculdade de Filosofia, Letras e Ciências Humanas, Universidade do Estado de São Paulo, São Paulo, 1980.

VELHO, Otávio Guilherme. Capitalismo autoritário e campesinato. Rio de Janeiro: Difel, 1995.

WEINSTEIN, Bárbara. A borracha na Amazônia: expansão e decadência (1850-1920). São Paulo: Hucitec; EDUSP, 1993. 